\title{
openheart Current state of cardiac troponin testing in Duchenne muscular dystrophy cardiomyopathy: review and recommendations from the Parent Project Muscular Dystrophy expert panel
}

\author{
Christopher F Spurney (D) , ${ }^{1}$ Deborah Ascheim, ${ }^{2}$ Lawrence Charnas (D) , ${ }^{3}$ \\ Linda Cripe, ${ }^{4}$ Kan Hor, ${ }^{4}$ Nicholas King, ${ }^{5}$ Kathi Kinnett, ${ }^{6}$ Elizabeth M McNally, ${ }^{7}$ \\ John-Michael Sauer, ${ }^{5}$ Lee Sweeney, ${ }^{8}$ Chet Villa, ${ }^{9}$ Larry W Markham ${ }^{10}$
}

To cite: Spurney CF, Ascheim D, Charnas L, et al. Current state of cardiac troponin testing in Duchenne muscular dystrophy cardiomyopathy: review and recommendations from the Parent Project Muscular Dystrophy expert panel. Open Heart 2021;8:e001592. doi:10.1136/ openhrt-2021-001592

Received 20 January 2021 Revised 17 February 2021 Accepted 5 March 2021
(D) Check for updates

(c) Author(s) (or their employer(s)) 2021. Re-use permitted under CC BY-NC. No commercial re-use. See rights and permissions. Published by BMJ.

For numbered affiliations see end of article.

Correspondence to Dr Christopher F Spurney; cspurney@childrensnational.org

\section{ABSTRACT}

Cardiac disease is now the leading cause of death in Duchenne muscular dystrophy (DMD). Clinical evaluations over time have demonstrated asymptomatic cardiac troponin elevations and acute elevations are associated with symptoms and cardiac dysfunction in DMD. Clinicians require a better understanding of the relationship of symptoms, troponin levels and progression of cardiac disease in DMD. As clinical trials begin to assess novel cardiac therapeutics in DMD, troponin levels in DMD are important for safety monitoring and outcome measures. The Parent Project Muscular Dystrophy convened an expert panel of cardiologists, scientists, and regulatory and industry specialists on 16 December 2019 in Silver Spring, Maryland and reviewed published and unpublished data from their institutions. The panel recommended retrospective troponin data analyses, prospective longitudinal troponin collection using high-sensitivity cardiac troponin I assays, inclusion of troponin in future clinical trial outcomes and future development of clinical guidelines for monitoring and treating troponin elevations in DMD.

\section{INTRODUCTION}

Cardiac troponin I (cTnI) and $\mathrm{T}(\mathrm{cTnT})$ are components of the contractile apparatus of myocardial cells expressed almost exclusively in the heart and are the preferred biomarkers for the evaluation of myocardial injury. ${ }^{1}$ Other biomarkers including creatine kinase MB (CK-MB) isoform are less sensitive and less specific, especially with associated skeletal muscle disease. ${ }^{2}$ Various causes lead to cardiac troponin release, including myocardial ischaemia often related to atherosclerotic coronary obstruction. Other non-ischaemic cardiac causes include heart failure, myocarditis and cardiomyopathies. Some systemic illnesses are also associated with troponin release, including pulmonary embolism, chronic kidney disease, sepsis and cardiotoxic agents. Troponin release can be acute or chronic and related to multisystem involvement. $^{23}$

Cardiomyopathy has become the leading cause of death in Duchenne muscular dystrophy (DMD). ${ }^{4}$ In DMD, case studies of acute-onset myocardial injury measured by troponin release are well documented dating back to the 1960 s, including a boy 10 years of age ${ }^{56}$ More recently, Hor et $a l^{7}$ described additional cases of acutely elevated troponin levels in subjects with DMD. Elevated troponin levels have been described in asymptomatic patients with DMD long before the development of the typical well-defined cardiac disease known to associate with DMD. ${ }^{8}$

Despite these historical reports, troponin elevations in patients with DMD are poorly understood and have unclear significance. With the support of the Parent Project Muscular Dystrophy (PPMD), a panel of experts in neuromuscular disease, adult and paediatric cardiology, Food and Drug Administration and industry convened to discuss the role of troponin in DMD clinical care and its use both as a safety and efficacy biomarker in DMD clinical trials.

\section{TROPONIN AND NEUROMUSCULAR DISEASES}

As noted, cardiac troponin elevations have been described in DMD since the 1960s. However, cTnT is considered less specific for myocardial injury as it is elevated in multiple 
neuromuscular disease conditions, likely reflecting a skeletal muscle source. ${ }^{9}{ }^{10}$ Chronic skeletal muscle disease can represent a potential cause of cTnT elevation, particularly when high-sensitivity (hs-cTnT) assay is used. ${ }^{112}$ cTnT was demonstrated to correlate better with creatine kinase and myoglobin levels than with cTnI, and assays showed cross-reactivity of cTnT antibodies with skeletal muscle TnT. These factors limit the use of $c \operatorname{TnT}$ and CK-MB for assessment of myocardial injury in DMD as cTnI is more specific. ${ }^{13} \mathrm{cTnI}$ is not expressed in human skeletal muscle during development or during regenerative muscle disease processes such as seen in DMD. ${ }^{14}$

The clinical significance of elevated cTnI in DMD and neuromuscular diseases continues to evolve. A recent study of 117 patients with DMD, Becker muscular dystrophy (BMD), DMD/BMD carrier, limb-girdle muscular dystrophy (LGMD), facioscapulohumeral dystrophy (FSHD) and myotonic dystrophy (DM) type I found a threefold increased risk of cardiac disease in subjects with an hs-cTnI level greater than $7.6 \mathrm{ng} / \mathrm{L}$ (Access High Sensitivity Troponin I Assay, BeckmanCoulter; normal <2.3ng/L). ${ }^{15}$ In a study of 53 subjects with dystrophic myopathies (including DMD, DMD carrier, BMD, LGMD 2A, FSHD), DM types I and II, and Becker/Thomsen myotonias, only three subjects, two with DMD and one with DM, had elevated cTnI levels and all three had evidence of cardiac disease. ${ }^{13}$ Other studies have also demonstrated increases in cTnI levels in DMD and BMD. ${ }^{16-18}$ However, other studies found normal cTnI levels in DMD. ${ }^{19-21}$ Elevated cTnT and cTnI levels were also detected in DMD/BMD carriers who are at risk of developing cardiomyopathy later in life. ${ }^{22-24} \mathrm{hs-cTnI}$ levels in DM type I were highly elevated in ambulatory subjects and predictive of cardiac dysfunction (Architect Stat Troponin Assay, Abbott).$^{25}$ Elevated cTnI levels were observed in patients with Friedreich's ataxia. ${ }^{26}$ Elevated troponin levels also occur in patients with spinal muscular atrophy (SMA), and transient increases in cTnI levels (up to $0.176 \mu \mathrm{g} / \mathrm{L}$; assay and normal limit not reported) of unclear significance were observed following Zolgensma infusion in clinical trials. This is an example of uncertainty regarding whether troponin levels are related to SMA or whether these reflect the clinical intervention. ${ }^{27}$

\section{PRECLINICAL DATA ON TROPONIN IN DYSTROPHIN-DEFICIENT ANIMAL MODELS}

Troponin serum levels were assessed in animal models of dystrophin deficiency, including the dystrophin-deficient $m d x$ mouse and related genetic models. cTnI was shown to be cardiac-specific and not present in the regenerating skeletal muscle of $m d x$ mice. $^{28}$ Martindale and Metzger ${ }^{29}$ measured decreased cTnI after membrane-stabilising poloxamer 188 therapy in $m d x$ mice. Buyse $e t a l^{30}$ found elevated cTnI levels in $m d x$ mice that were decreased after idebenone therapy. In the dystrophin-utrophin double knockout mouse, Lopez et $a \hat{l}^{1}$ showed decreased serum cTnT after whole body periodic acceleration.
The dystrophin-deficient golden retriever muscular dystrophy (GRMD) large animal model recapitulates some aspects of the human cardiomyopathy course better than the $m d x$ model. Townsend $e t a l^{2}$ administered a chronic infusion of a membrane-sealing agent to severely affected GRMD dogs and found decreased troponin I levels and reduced myocardial fibrosis. A case report by Schneider $e t a \hat{l}^{33}$ described a GRMD dog exhibiting acute cardiac disease including tachyarrhythmia associated with significant increase in troponin I, NT-probrain natriuretic peptide and progression over a 3-year period to severe dilated cardiomyopathy. In ongoing experiments, monthly troponin I values obtained from dystrophin-deficient dogs revealed periodic spikes in troponin levels and an increase in the number of spikes with age correlated with cardiac involvement. Lower troponin levels were obtained in older dogs with loss of cardiac mass (Sweeney, unpublished data, 2020). The preclinical data support a role for monitoring troponin levels during therapeutic trials, but further recommendations for preclinical studies were not the focus of the expert panel.

\section{CLINICAL DATA ON TROPONIN IN DMD}

Troponin levels are used less clinically in paediatrics due to low prevalence of ischaemic cardiac disease. In order to understand the relevance of troponin levels in DMD, it is important to determine troponin levels in healthy children. In 2009, the CALIPER (Canadian Laboratory Initiative on Pediatric Reference Intervals) study of healthy children and adolescents published reference laboratory values for paediatric subjects including cTnI using the Abbott Architect ci8200. ${ }^{34} \mathrm{cTnI}$ levels had maximal measures of $0.176 \mu \mathrm{g} / \mathrm{L}$ in subjects less than 1 year old, 0.112 $\mu \mathrm{g} / \mathrm{L}$ in subjects $1-5$ years old, $0.018 \mu \mathrm{g} / \mathrm{L}$ in subjects 6-10 years old, $0.663 \mu \mathrm{g} / \mathrm{L}$ in subjects $11-14$ years old, and $0.401 \mu \mathrm{g} / \mathrm{L}$ in subjects $15-20$ years old. Due to these low levels in normal paediatric patients, Caselli et $a l^{35}$ used hs-cTnI testing (Architect Stat High-Sensitivity TnI, Architect i1000SR platform, Abbott Diagnostics) and found approximately $13 \%$ of all subjects aged $<1$ month to $<18$ years had non-detectable levels. hs-cTnI levels were highest in the first month of life (mean $37.5 \mathrm{ng} / \mathrm{L}$ ) and decreased with age (infants: mean $19.4 \mathrm{ng} / \mathrm{L}$; children 1-10 years: mean $6.5 \mathrm{ng} / \mathrm{L}$; adolescents: mean $3.1 \mathrm{ng} / \mathrm{L}$ ). Males showed significantly higher hs-cTnI levels than females. An earlier study using a similar hs-cTnI assay (precommercial Architect Stat hs-cTnI Assay, Abbott Diagnostics) demonstrated physiological variability in healthy subjects aged 8-12 years old with multiple measures in the range of $0 \%-136 \%$, with a median of $33 \%{ }^{36}$ These studies support the presence of cTnI release in the healthy paediatric population likely related to physiological myocardial growth and demonstrate the need for assay-specific norms related to gender and age. Thus, standardisation of troponin assays and development of 
Table 1 Cross-sectional cTnl levels, per cent ejection fraction and cystatin $\mathrm{C}$ levels of asymptomatic subjects with DMD demonstrating elevations from normal level of $0.02 \mathrm{ng} /$ $\mathrm{mL}$ (ELISA assay; Siemens Dimension Analyzer, Siemens Laboratory Diagnostics, Tarrytown, New York) and no relation to age, systolic function or kidney function

\begin{tabular}{llll}
\hline Age (years) & $\begin{array}{l}\text { Serum cTnl } \\
\text { (ng/mL) }\end{array}$ & $\begin{array}{l}\text { Per cent } \\
\text { ejection } \\
\text { fraction }\end{array}$ & $\begin{array}{l}\text { Cystatin C } \\
\text { level (mg/L) }\end{array}$ \\
\hline 8 & 0.04 & 57 & 0.66 \\
\hline 9 & 0.04 & 60 & 0.65 \\
\hline 10 & 0.02 & 45 & 0.63 \\
10 & 0.07 & 64 & 0.7 \\
10 & 0.02 & 51 & 0.53 \\
10 & 0.02 & 52 & 0.75 \\
11 & 0.06 & 58 & 0.82 \\
\hline 12 & 0.02 & 60 & 0.49 \\
\hline 15 & 0.88 & 50 & 0.87 \\
15 & 0.02 & 64 & 0.55 \\
\hline 17 & 0.02 & 58 & 0.55 \\
\hline 17 & 0.07 & 63 & 0.44 \\
\hline 18 & 0.01 & 59 & 0.45 \\
\hline 19 & 0.05 & 49 & 0.65 \\
\hline 19 & 0.72 & 48 & 0.6 \\
\hline 24 & 0.07 & 39 & 0.79 \\
\hline
\end{tabular}

Cystatin C normal range: $0.05-1 \mathrm{mg} / \mathrm{L}$.

cTnl, cardiac troponin I; DMD, Duchenne muscular dystrophy.

normal values are important foundations for the evaluation of myocardial injury in DMD.

In a recent publication, Voleti et $a l^{8}$ described cTnI levels and the relationship to cardiac magnetic resonance (CMR) imaging results in DMD. Data from this observation cohort of asymptomatic participants with DMD were obtained at the time of CMR, and the cTnI levels from participants with a single measure are shown in table 1 , ranging from $0.02 \mathrm{ng} / \mathrm{mL}$ to $0.88 \mathrm{ng} / \mathrm{mL}$ (ELISA assay; Siemens Dimension Analyzer; normal range $<0.04 \mathrm{ng} /$ $\mathrm{mL})$.

This study also showed that subjects with DMD with mild late gadolinium enhancement (LGE) on CMR had significantly increased troponin levels $(0.28 \pm 0.38 \mathrm{ng} / \mathrm{mL})$ compared with those with no LGE $(0.05 \pm 0.08 \mathrm{ng} / \mathrm{mL}){ }^{8}$ Interestingly, the troponin levels decreased in subjects with DMD with moderate to severe LGE $(0.11 \pm 0.14 \mathrm{ng} /$ $\mathrm{mL}$ ). This may be related to a loss of susceptible myocardium to damage over time. Additional cohort data are provided in table 2, showing participants with DMD with longitudinal cTnI levels studied at Children's National Hospital (NCT02921321). These data demonstrate the heterogeneity of troponin levels in DMD, noting that levels may increase, decrease or remain unchanged over time. Based on these findings, it is necessary to more systematically collect data across all ages and DMD clinical courses.

While these data begin to elucidate the chronic cTnI levels in asymptomatic patients with DMD, recent reports focused on acute elevations of cTnI in DMD associated with symptoms including chest pain. An important case series described eight subjects with DMD, aged 9-23 years, who presented with episodes of acute chest pain and transient elevations of cTnI. ${ }^{7}$ The subjects had normal baseline ECGs that evolved to show ST segment elevations in leads II, III and aVF in seven subjects, with additional elevations in V4-V6 in two subjects and V1-V4 in one subject. However, these elevations were not consistent with any specific coronary distributions. Troponin levels ranged from $31 \mathrm{ng} / \mathrm{mL}$ to $62 \mathrm{ng} / \mathrm{mL}$ (assay not reported; normal $<0.03 \mathrm{ng} / \mathrm{mL}$ ) and normalised over 4 days. All subjects demonstrated a decrease in systolic function during the acute episode. Two subjects had a cardiac CT scan and two subjects underwent cardiac catheterisation with no coronary abnormalities identified. Importantly, the pattern of delayed enhancement on GMR in all subjects was not consistent with ischaemia. All subjects received supportive care with traditional cardiac medications and follow-up continues.

Another case report described an 18-year-old subject with DMD who presented with chest pain, abnormal ECG with significant ST segment elevations in leads I, II, III, $\mathrm{aVF}$ and V6, and acutely elevated cTnI level of $39 \mathrm{ng} / \mathrm{dL}$ that later peaked at $73 \mathrm{ng} / \mathrm{dL}$ (assay not reported; normal range $<0.4 \mathrm{ng} / \mathrm{dL}$ ). ${ }^{37}$ The subject had global hypokinesis and normal coronary angiography, and LGE was evident on CMR. The onset of symptoms temporally correlated with a shift in glucocorticoid dosing and, potentially, an acute inflammatory reaction. His symptoms resolved with restarting steroids and supportive care. A second case report of an 11-year-old boy with DMD presenting with chest pain, decreased cardiac function, elevated cTnT and normal coronary angiography also improved after increasing his steroid dose. ${ }^{38}$ Two more 13-year-old boys with DMD were described with ST segment elevations and troponin changes. ${ }^{39} 40$ A similar clinical picture was also noted after an episode of respiratory failure in a patient with DMD. ${ }^{41}$ These reports demonstrate a unique presentation of acutely elevated troponin levels with abnormal ECGs in DMD and no evidence of coronary artery disease. The limited utility of invasive diagnostic cardiac catheterisation should only be considered in specific cases where a known cause of ischaemia is under consideration.

\section{CLINICAL MONITORING OF TROPONIN IN DMD}

Current recommendations for cardiac care of patients with DMD include a cardiac evaluation at the time of diagnosis, including physical examination, ECG and echocardiogram. ${ }^{42-46}$ Similar evaluations should occur every 1-2 years in asymptomatic children until age 10, when yearly evaluations are recommended. Symptomatic children should be evaluated more frequently as determined by 
Table 2 Longitudinal cTnl levels and per cent ejection fraction in asymptomatic subjects with DMD over a 3-year follow-up period demonstrating variable changes in troponin levels and systolic function over time

\begin{tabular}{|c|c|c|c|c|c|c|}
\hline Subject & Age (years) & Test & Baseline & 1 year & 2 years & 3 years \\
\hline \multirow[t]{2}{*}{1} & 8 & cTnl & 0.02 & 0.02 & - & - \\
\hline & & $\%$ EF & 63 & 60 & - & - \\
\hline \multirow[t]{2}{*}{2} & 8 & cTnl & 0.02 & 0.02 & 0.02 & - \\
\hline & & $\%$ EF & 66 & 56 & 67 & - \\
\hline \multirow[t]{2}{*}{3} & 10 & cTnl & 0.22 & 0.06 & - & - \\
\hline & & $\%$ EF & 63 & 56 & - & - \\
\hline \multirow[t]{2}{*}{4} & 12 & cTnl & 0.06 & 0.02 & 0.02 & - \\
\hline & & $\%$ EF & 57 & 52 & 54 & - \\
\hline \multirow[t]{2}{*}{5} & 12 & cTnl & 0.05 & 0.64 & - & - \\
\hline & & $\%$ EF & 60 & 50 & - & - \\
\hline \multirow[t]{2}{*}{6} & 12 & cTnl & 0.32 & - & - & 0.21 \\
\hline & & $\%$ EF & 60 & - & - & 40 \\
\hline \multirow[t]{2}{*}{7} & 12 & cTnl & 0.02 & - & - & 0.02 \\
\hline & & $\%$ EF & 66 & - & - & 54 \\
\hline \multirow[t]{2}{*}{8} & 14 & cTnl & 0.05 & - & 0.01 & - \\
\hline & & $\%$ EF & 54 & - & 53 & - \\
\hline \multirow[t]{2}{*}{9} & 14 & cTnl & 0.01 & - & 0.02 & 0.02 \\
\hline & & $\%$ EF & 41 & - & 32 & 36 \\
\hline \multirow[t]{2}{*}{10} & 15 & cTnl & 0.02 & 0.02 & 0.02 & - \\
\hline & & $\%$ EF & 67 & 55 & 61 & - \\
\hline \multirow[t]{2}{*}{11} & 17 & cTnl & 0.02 & 0.06 & - & - \\
\hline & & $\%$ EF & 51 & 43 & - & - \\
\hline \multirow[t]{2}{*}{12} & 17 & cTnl & 0.37 & - & 0.31 & 0.40 \\
\hline & & $\%$ EF & 52 & - & 60 & 51 \\
\hline \multirow[t]{2}{*}{13} & 19 & cTnl & 0.28 & 0.14 & 0.05 & 0.02 \\
\hline & & $\%$ EF & 54 & 49 & 48 & 41 \\
\hline \multirow[t]{2}{*}{14} & 21 & cTnl & 0.02 & 0.02 & 0.02 & - \\
\hline & & $\%$ EF & 52 & 52 & 49 & - \\
\hline \multirow[t]{2}{*}{15} & 27 & cTnl & 0.03 & 0.03 & - & - \\
\hline & & $\% \mathrm{EF}$ & 61 & 56 & - & - \\
\hline
\end{tabular}

cTnl, cardiac troponin I (ng/mL); DMD, Duchenne muscular dystrophy; \%EF, per cent ejection fraction.

the provider. Periodic use of advanced imaging including CMR and ambulatory monitoring is also recommended.

There are no current recommendations for the routine monitoring of cTnI levels in DMD. Therefore, the distribution of troponin elevations in the DMD population is difficult to determine, in part because there is clinical ascertainment bias towards testing only those who are symptomatic. However, there are also those with asymptomatic chronic lower level elevations and older individuals with abnormal left ventricular function and acute changes in the setting of other illness (eg, sepsis, pneumonia, fracture). Patients with chronic kidney disease can demonstrate increased levels of hs-cTnI and hs-cTnT at baseline and kidney disease can develop in DMD ${ }^{47}$ Creatinine as a marker of renal function has limited value in
DMD because of reduced muscle mass. However, cystatin $\mathrm{C}$, a non-glycosylated protein unaffected by muscle mass, is an additional biomarker of nephrotoxicity in the DMD population and elevated levels were demonstrated in a subject with DMD in renal failure. ${ }^{48}$ Cystatin $\mathrm{C}$ levels are included in table 1, demonstrating normal kidney function associated with variable cTnI elevations. The diagnostic value of cTnI may be more difficult to discern in patients with DMD with kidney failure, and treating physicians would need to consider changes from baseline and use higher cut-off values. ${ }^{47}$ This demonstrates another scenario where it is important to collect longitudinal baseline data and consider cystatin $\mathrm{C}$ levels to correlate troponin with kidney function. 
hs-cTnI levels are commonly used in clinical evaluations of acute coronary syndrome and chest pain in adult patients. The Atherosclerosis Risk In Communities Study concluded that elevated hs-cTnI is strongly associated with increased global cardiovascular disease incidence in the general population, independent of traditional risk factors. ${ }^{49}$ Since many patients with DMD will present to adult and community hospitals, hs-cTnI levels have replaced traditional troponin assays and are recommended in the Fourth Universal Definition of Myocardial Infarction (2018). ${ }^{1}$ This will provide new data to physicians to help with clinical decisions and potential risk stratification even in asymptomatic subjects with DMD. So while it is not yet known how the improved analytical sensitivity will impact clinical care in DMD, it will be paramount to include hs-cTnI analyses in future evaluations. ${ }^{50}$

Increases in cTnI levels could signal changes in therapeutic approaches. While standard of care now includes consideration of ACE inhibitors around age 10, initiation of this medication could begin sooner if elevated troponin levels are identified. ${ }^{43}$ In addition, mineralocorticoid receptor antagonists showed benefits in slowing the loss of myocardial strain in subjects with DMD and could be useful. ${ }^{51-53}$ Some of these benefits are related to membrane stabilisation properties that could also slow troponin release from myocardial cells. ${ }^{54-56}$ Increased steroid dosing showed benefits in two case reports. ${ }^{37} 38$ A new steroid derivative therapeutic also demonstrated membrane stabilisation properties and could provide an alternative to steroid therapy in subjects with elevated cTnI levels. ${ }^{57} 58$ One agent or a strategic combination of these therapeutics could provide new benefits to children with DMD with elevated troponin levels.

In order to best direct clinical care, it will be important to understand how these transient spikes or chronic elevations may change with age, cardiac mass, respiratory disease and/or skeletal muscle function. Further research is needed to determine the potential mechanism(s) including coronary spasm, inflammation, arrhythmia, volume overload, elevated heart rate and/ or elevated blood pressure behind troponin elevations, and the potential impact of the interplay with skeletal and respiratory muscle function is critical to elucidate. Once better understood, incorporating the related basic science will be essential in determining appropriate therapies.

\section{TROPONIN MONITORING AS A DMD CLINICAL TRIAL BIOMARKER}

The role of cardiac troponin as an appropriate clinical trial biomarker in DMD is unclear at this time. Monitoring of cardiac troponin levels as a safety marker may be important. The use of troponin as a safety outcome marker would require determining normal values and thresholds for normal and acceptable fluctuations for both cardiac and non-cardiac (skeletal muscle) directed therapies. In a trial involving a single baseline intracoronary injection of allogeneic cardiosphere-derived cells, the authors noted periprocedural elevations in cTnI, but also noted two subjects in both the usual care and treatment groups that demonstrated elevated cTnI levels during the 12-month follow-up period, described as 'greater than $\times 5$ composite 99th percentile or at least $20 \%$ elevated beyond baseline'. Once recovered from the intervention, these asymptomatic elevations were not regarded as adverse events. ${ }^{59}$

In a clinical trial of a monoclonal antimyostatin antibody domagrozumab (NCT02310763), cTnI was measured as a clinical laboratory biomarker in 120 participants with DMD. Approximately $20 \%$ of participants had cTnI values above $0.3 \mathrm{ng} / \mathrm{mL}$ at baseline (assay not reported; normal $\leq 0.03 \mathrm{ng} / \mathrm{mL}$ ); elevations were seen at all timepoints measured in the trial and elevations were not sustained or associated with clinical symptoms. The highest value seen was approximately $3.5 \mathrm{ng} / \mathrm{mL}$. Increased cTnI levels regarded as adverse events were seen in two subjects who received placebo and one subject who received treatment. ${ }^{6061}$ Additional analysis is ongoing and the role of troponin as a biomarker for safety, treatment outcome, susceptibility to risk or response predictiveness needs further study.

\section{FUTURE DIRECTIONS}

The expert panel noted several areas to focus efforts to further develop an understanding of cTnI in DMD (figure 1) - Figure 1 seems blurry, any way to improve? The first area identified was to leverage existing data sets to perform new data analyses. Current data from different studies including clinical trials, longitudinal observational studies and registries can be used to create a consistent data structure for analysis with the goal of developing an actionable drug development tool and a clinically meaningful screening tool. This approach would need to use existing infrastructure to involve these different entities. The Advanced Cardiac Therapies Improving Outcomes Network may illustrate such a path forward for DMD. The network's goal is to improve critical outcomes for children and adult congenital heart disease patients with heart failure by developing an international collaborative learning health system that unites all key stakeholders (patients, families, clinicians, researchers and industry). While initially addressing heart failure, the approach of transforming an unstandardised clinical paradigm can provide the infrastructure to rapidly disseminate critical information to families and clinicians. This is quite similar to the current state of cTnI monitoring in DMD. The network has the expertise to determine the availability of cTnI data or samples from previous clinical trials, contact individual trial sites to obtain necessary consent, leverage social media networks within the DMD community and involve principal investigators.

The panel recognises the importance of prospective data collection. This approach may begin with a survey of centres involved with DMD cardiac care regarding the use of cTnI monitoring in both asymptomatic and 


\begin{tabular}{|c|c|}
\hline \multicolumn{2}{|r|}{ I. Retrospective data collection } \\
\hline - Integr & $\begin{array}{l}\text { ting and harmonizing existing data sets should be an immediate goal } \\
\text { Create DMD troponin steering committee to determine priorities and processes for } \\
\text { reviewing retrospective data. } \\
\text { Use PPMD developed Duchenne Outcomes Research Interchange (DORI), a patient- } \\
\text { data warehouse with } 10 \text { years of data } \\
\text { Leverage existing infrastructure (ACTION; Pediatric Health Information System (PHIS); } \\
\text { institutional electronic medical records) to expand data acquisition }\end{array}$ \\
\hline \multicolumn{2}{|c|}{ II. Prospective data collection } \\
\hline \multicolumn{2}{|c|}{$\begin{array}{l}\text { - Develop collaborative multi-center prospective research protocol to collect longitudinal } \\
\text { troponin and other potential serum biomarkers } \\
\text { Incorporate initial clinician survey through DMD clinical care networks regarding } \\
\text { screening practices including troponin assays used and therapeutic responses } \\
\text { Obtaining baseline and semi-annual/ annual troponin values in all DMD patients } \\
\text { - Samples must be unbiased and not obtained only in response to symptoms } \\
\text { - } \text { Recommend use of hs-cTnl assays } \\
\text { Consider simultaneously obtaining other meaningful and exploratory serum } \\
\text { biomarkers to contextualize troponin values } \\
\text { Combining data across systems will require the ability to convert/harmonize assays } \\
\text { - An immediate goal should be to seek agreement among children's hospitals } \\
\text { regarding use of hs-cTnl assay or agreement on a process for } \\
\text { standardizing/comparing assays } \\
\text { The ACTION network can lead the initial process of determining which assays } \\
\text { are currently used by different centers }\end{array}$} \\
\hline \multicolumn{2}{|c|}{ III. Clinical trials } \\
\hline \multicolumn{2}{|c|}{$\begin{array}{l}\text { - Incorporate troponin as an exploratory biomarker, rather than a safety biomarker, in clinical } \\
\text { trials }\end{array}$} \\
\hline $\begin{array}{l}0 \\
0 \\
0\end{array}$ & $\begin{array}{l}\text { Serum samples obtained in clinical trials must be stored appropriately and made } \\
\text { available for future analyses } \\
\text { A process for sharing data from clinical trials should be established } \\
\text { - Critical Path Institute can establish a data contribution agreement } \\
\text { Longitudinal patient follow-up after clinical trials with appropriate permissions must } \\
\text { be established }\end{array}$ \\
\hline \multicolumn{2}{|c|}{ IV. Development of clinical guideline } \\
\hline \multicolumn{2}{|c|}{$\begin{array}{l}\text { - Develop expert consensus clinical guidelines for monitoring and treatment of troponin levels } \\
\text { in DMD }\end{array}$} \\
\hline 0 & $\begin{array}{l}\text { Determine the lower limit of a concerning elevation in troponin } \\
\text { - Determine whether absolute values or change(s) in values are more } \\
\text { important } \\
\text { Consensus regarding treatment recommendations for abnormally elevated troponin } \\
\text { values in asymptomatic patients with normal diagnostic testing and symptomatic } \\
\text { patients with abnormal diagnostic testing }\end{array}$ \\
\hline
\end{tabular}


symptomatic subjects with DMD. The panel recommended a multicentre collaborative research protocolbased assessment for monitoring cTnI levels on a consistent time frame, such as at the time of cardiac imaging, but not more frequently than every 6 months, and focusing on hs-cTnI testing as feasible. The expert panel felt this information would be clinically useful as it could help provide context for interpretation of troponin levels monitored during an acute event, should it occur. Further discussion should focus on other serum or imaging biomarkers that may prove important tools to monitor cardiac function in DMD. Serum ST2 levels were increased in subjects with DMD with cardiomyopathy and matrix metallopeptidase (MMP) 9 was elevated in subjects with DMD compared with normal controls. ${ }^{62}$ Serum MMP7 was increased in subjects with DMD with evidence of fibrosis compared with normal subjects with DMD and controls. ${ }^{63}$ Novel imaging biomarkers using CMR T1 and T2 imaging should provide further meaningful context for cTnI levels. ${ }^{64}$

The optimal approach should also incorporate cTnI levels in developing clinical trials. In fact, consideration should be given to including cTnI as an exploratory outcome rather than a safety biomarker. Information obtained in clinical trials may ultimately have great value, but questions remain regarding how to interpret values obtained in clinical trials for safety monitoring. For example, until the natural history of the disease is well understood, it would be difficult to determine whether an elevated level obtained in a clinical trial represents an adverse event or just natural variation. Based on an accumulation of data, future clinical trials will be better informed on how to determine a critical level at which an elevated troponin level becomes a safety concern. A process for sharing real-time cTnI results from clinical trials should be established incorporating existing infrastructure such as the Critical Path Institute.

The above approaches will ultimately inform clinical guidelines. Based on the current knowledge base, the expert panel recommends clinical monitoring and supportive care of patients with DMD with elevated troponin levels. Consideration should be given to optimising medical management with ACE inhibitors, betablockers and/or mineralocorticoid receptor antagonists based on cardiac function, degree of myocardial fibrosis and cardiomyopathy trajectory. These patients are at low risk of atherosclerotic disease or coronary thrombosis and urgent coronary angiography is not recommended. By establishing standardised timing and methods for routine cTnI monitoring, clinicians will gain further insight into the progression of myocardial disease in DMD. Guidelines would include a cTnI threshold and the appropriate response to above threshold levels, minimising the use of coronary angiography in these patients. These guidelines would inform the entire medical community outside of academic centres and improve quality of care in community hospitals where children with DMD may present with chest pain episodes. These guidelines would also inform the DMD parent community and reassure parents by clarifying the appropriate evaluation and treatment during these stressful events. This mutual understanding of presentation and treatment will improve care and family support and optimise outcomes for this vulnerable population.

Based on this meeting summary and the reference literature, there remain limitations. Cardiac disease is an important feature in DMD; however, it is not clear if cardiac troponins are a reliable biomarker for monitoring cardiac health in patients with associated chronic skeletal muscle disease. Potential cross-reactivity in assays for cTnI and cTnT must be improved to differentiate from skeletal muscle damage. There is not a universal standard for cTnI monitoring and paediatric hospitals use both traditional and high-sensitivity troponin assays less frequently, limiting data comparison across centres. Lastly, a more comprehensive understanding and characterisation of myocardial injury that is occurring in DMD is necessary to comprehend its relation to cTnI release.

In conclusion, further understanding of cTnI levels in DMD is necessary to best monitor and treat the cardiomyopathy associated with DMD. Limited data and case reports have demonstrated both chronic asymptomatic mild cTnI elevations and acute symptomatic often striking cTnI elevations in DMD. The cTnI levels usually normalise, but the lasting effects of the associated myocardial injury are not well understood. As cardiac disease is now the leading cause of death in DMD, this expert panel strongly encourages retrospective troponin data analyses, prospective longitudinal troponin collection using highsensitivity cTnI assays, inclusion of troponin in future clinical trial outcomes and future development of clinical guidelines for monitoring and treating troponin elevations in DMD.

\section{Author affiliations}

${ }^{1}$ Children's National Heart Institute, Children's National Hospital, Washington, District of Columbia, USA

${ }^{2} \mathrm{D} 2 \mathrm{~A}$, Los Angeles, California, USA

${ }^{3}$ Clinical Research Rare Neurology Disease, Pfizer, Cambridge, Massachusetts, USA

${ }^{4}$ The Heart Center, Nationwide Children's Hospital, Columbus, Ohio, USA

${ }^{5}$ Critical Path Institute, Tucson, Arizona, USA

${ }^{6}$ Parent Project Muscular Dystrophy, Hackensack, New Jersey, USA

${ }^{7}$ Center for Genetic Medicine, Northwestern Medicine, Chicago, Illinois, USA

${ }^{8}$ Department of Pharmacology and Therapeutics, University of Florida, Gainesville, Florida, USA

${ }^{9}$ Cardiology, Cincinnati Children's Hospital Medical Center, Cincinnati, Ohio, USA

${ }^{10}$ Pediatrics, Division of Pediatric Cardiology, Riley Hospital for Children at Indiana University Health, Indianapolis, Indiana, USA

Contributors CS was responsible for data regarding troponin levels, clinical evaluation of troponin levels and imaging biomarkers, and wrote and revised the manuscript. DA was responsible for development of future recommendations and revised the manuscript. LCh was responsible for data regarding troponin levels in clinical trials and revised the manuscript. LCr was responsible for evaluation of troponin levels in clinical and research subjects and revised the manuscript. $\mathrm{KH}$ was responsible for imaging biomarkers in relation to troponin and clinical evaluation of troponin and revised the manuscript. NK and JM-S were responsible for developing future recommendations regarding analysis of existing data and prospective data collection and revised the manuscript. KK was responsible for foundation involvement in clinical care guidelines and trial design and revised 
the manuscript. EM was responsible for troponin assay analysis and clinical evaluation of troponin levels and revised the manuscript. LS was responsible for analysis of troponin levels in preclinical models of dystrophin deficiency. CV was responsible for clinical evaluation of troponin levels and development of future recommendations and revised the manuscript. LWM was responsible for clinical evaluation of troponin levels and recommendations for clinical guidelines and revised the manuscript.

Funding Funding for this meeting was provided by the Parent Project Muscular Dystrophy (PPMD).

Competing interests DA: consultant to PPMD/I-ACT for Children, no relevant conflicts. LC: employee and shareholder of Pfizer, Inc. NK and J-MS: Critical Path Institute is supported by the Food and Drug Administration (FDA) of the US Department of Health and Human Services (HHS) and is $62 \%$ funded by FDA/HHS totalling $\$ 14448917$ and $28 \%$ funded by non-government source(s) totalling $\$ 8$ 669646 . The contents are those of the author(s) and do not necessarily represent the official views of, nor an endorsement, by FDA/HHS, or the US Government. EM: consultant to AstraZeneca, Amgen, Avidity, 4D Molecular Therapeutics, Pfizer, Janssen, Cytokinetics, Exonics and Invitae; grant support from NIH and Department of Defense.

Patient consent for publication Not required.

Provenance and peer review Not commissioned; externally peer reviewed.

Data availability statement All data relevant to the study are included in the article or uploaded as supplementary information.

Open access This is an open access article distributed in accordance with the Creative Commons Attribution Non Commercial (CC BY-NC 4.0) license, which permits others to distribute, remix, adapt, build upon this work non-commercially, and license their derivative works on different terms, provided the original work is properly cited, appropriate credit is given, any changes made indicated, and the use is non-commercial. See: http://creativecommons.org/licenses/by-nc/4.0/.

\section{ORCID iDs}

Christopher F Spurney http://orcid.org/0000-0003-2493-5735

Lawrence Charnas http://orcid.org/0000-0002-4133-7959

\section{REFERENCES}

1 Thygesen K, Alpert JS, Jaffe AS, et al. Fourth universal definition of myocardial infarction (2018). J Am Coll Cardiol 2018;72:2231-64. doi:10.1016/j.jacc.2018.08.1038

2 Wang $\mathrm{H}$, Liu S, Xing Y-lin, et al. [The limitation of MB isoenzyme of creatine kinase mass in assess myocardial injury with muscular disease]. Zhongguo Wei Zhong Bing Ji Jiu Yi Xue 2011;23:723-6.

3 Harrison N, Favot M, Levy P. The role of troponin for acute heart failure. Curr Heart Fail Rep 2019;16:21-31.

4 Passamano L, Taglia A, Palladino A, et al. Improvement of survival in Duchenne muscular dystrophy: retrospective analysis of 835 patients. Acta Myol 2012;31:121-5.

5 Shapiro HS, Ribeilimal J, Wendt VE. Myocardial infarction in progressive muscular dystrophy. Am J Cardiol 1964;14:232-6.

6 Fiorista F, Brambilla G, Saviotti M, et al. Myocardial infarction in a child aged ten with Duchenne muscular dystrophy. $Z$ Kardiol 1981;70:784-8.

7 Hor KN, Johnston P, Kinnett K, et al. Progression of Duchenne cardiomyopathy presenting with chest pain and troponin elevation. $J$ Neuromuscul Dis 2017:4:307-14.

8 Voleti S, Olivieri L, Hamann K, et al. Troponin I levels correlate with cardiac Mr LGE and native T1 values in Duchenne muscular dystrophy cardiomyopathy and identify early disease progression. Pediatr Cardiol 2020;41:1173-9.

9 Rittoo D, Jones A, Lecky B, et al. Elevation of cardiac troponin T, but not cardiac troponin I, in patients with neuromuscular diseases: implications for the diagnosis of myocardial infarction. J Am Coll Cardiol 2014;63:2411-20.

10 Wens SCA, Schaaf GJ, Michels M, et al. Elevated plasma cardiac troponin $\mathrm{T}$ levels caused by skeletal muscle damage in Pompe disease. Circ Cardiovasc Genet 2016;9:6-13.

11 Giannitsis E, Mueller C, Katus HA. Skeletal myopathies as a noncardiac cause of elevations of cardiac troponin concentrations. Diagnosis 2019;6:189-201.

12 Jaffe AS, Vasile VC, Milone M, et al. Diseased skeletal muscle: a noncardiac source of increased circulating concentrations of cardiac troponin T. J Am Coll Cardiol 2011;58:1819-24.

13 Schmid J, Liesinger L, Birner-Gruenberger R, et al. Elevated cardiac troponin $\mathrm{T}$ in patients with skeletal myopathies. J Am Coll Cardiol 2018;71:1540-9.
14 Bodor GS, Porterfield D, Voss EM, et al. Cardiac troponin-I is not expressed in fetal and healthy or diseased adult human skeletal muscle tissue. Clin Chem 1995;41:1710-5.

15 Nikhanj A, Nichols BM, Wang K, et al. Evaluating the diagnostic and prognostic value of biomarkers for heart disease and major adverse cardiac events in patients with muscular dystrophy. Eur Heart J Qual Care Clin Outcomes 2020. doi:10.1093/ehjqcco/qcaa059. [Epub ahead of print: $20 \mathrm{Jul} 2020]$.

16 Sadek AA, Mahmoud SM, El-Aal MA, et al. Evaluation of cardiac functions in children with Duchenne muscular dystrophy: a prospective case-control study. Electron Physician 2017:9:5732-9.

17 Zhang $\mathrm{Y}$, Wang $\mathrm{H}$, Yu X, et al. [Comparison analysis of muscle enzymes in children with myocarditis and Duchene/Becker muscular dystrophy]. Zhong Nan Da Xue Xue Bao Yi Xue Ban 2016;41:984-91.

18 Matsumura T, Saito T, Fujimura H, et al. Cardiac troponin I for accurate evaluation of cardiac status in myopathic patients. Brain Dev 2007;29:496-501.

19 Hammerer-Lercher A, Erlacher P, Bittner R, et al. Clinical and experimental results on cardiac troponin expression in Duchenne muscular dystrophy. Clin Chem 2001;47:451-8.

20 Buyse GM, Goemans N, van den Hauwe M, et al. Idebenone as a novel, therapeutic approach for Duchenne muscular dystrophy: results from a 12 month, double-blind, randomized placebocontrolled trial. Neuromuscul Disord 2011;21:396-405.

21 Castro-Gago M, Gómez-Lado C, Eirís-Puñal J. Cardiac troponin I for accurate evaluation of cardiac status in myopathic patients. Brain Dev 2009;31:184.

22 De Pooter J, Vandeweghe J, Vonck A, et al. Elevated troponin T levels in a female carrier of Duchenne muscular dystrophy with normal coronary angiogram: a case report and review of the literature. Acta Cardiol 2012;67:253-6.

23 Schade van Westrum SM, Hoogerwaard EM, Dekker L, et al. Cardiac abnormalities in a follow-up study on carriers of Duchenne and Becker muscular dystrophy. Neurology 2011;77:62-6.

24 Hoogerwaard EM, Schouten Y, van der Kooi AJ, et al. Troponin T and troponin I in carriers of Duchenne and Becker muscular dystrophy with cardiac involvement. Clin Chem 2001;47:962-3.

25 Hamilton MJ, Robb Y, Cumming S, et al. Elevated plasma levels of cardiac troponin-I predict left ventricular systolic dysfunction in patients with myotonic dystrophy type 1: a multicentre cohort followup study. PLoS One 2017;12:e0174166.

26 Friedman LS, Schadt KA, Regner SR, et al. Elevation of serum cardiac troponin I in a cross-sectional cohort of asymptomatic subjects with Friedreich ataxia. Int J Cardiol 2013;167:1622-4.

27 Zolgensma prescribing information. Available: https://www.avexis. com/us/Content/pdf/ prescribing_information.pdf [Accessed 20 Jul 2020].

28 Hammerer-Lercher A, Erlacher P, Bittner R, et al. Clinical and experimental results on cardiac troponin expression in Duchenne muscular dystrophy. Clin Chem 2001;47:451-8.

29 Martindale JJ, Metzger JM. Uncoupling of increased cellular oxidative stress and myocardial ischemia reperfusion injury by directed sarcolemma stabilization. J Mol Cell Cardiol 2014;67:26-37.

30 Buyse GM, Van der Mieren G, Erb M, et al. Long-term blinded placebo-controlled study of SNT-MC17/idebenone in the dystrophin deficient $m d x$ mouse: cardiac protection and improved exercise performance. Eur Heart J 2009;30:116-24.

31 Lopez JR, Kolster J, Zhang R, et al. Increased constitutive nitric oxide production by whole body periodic acceleration ameliorates alterations in cardiomyocytes associated with utrophin/dystrophin deficiency. J Mol Cell Cardiol 2017;108:149-57.

32 Townsend D, Turner I, Yasuda S, et al. Chronic administration of membrane sealant prevents severe cardiac injury and ventricular dilatation in dystrophic dogs. J Clin Invest 2010;120:1140-50.

33 Schneider SM, Coleman AE, Guo L-J, et al. Suspected acute myocardial infarction in a dystrophin-deficient dog. Neuromuscul Disord 2016;26:361-6.

34 Chan MK, Seiden-Long I, Aytekin M, et al. Canadian laboratory initiative on pediatric reference interval database (CALIPER): pediatric reference intervals for an integrated clinical chemistry and immunoassay analyzer, Abbott architect ci8200. Clin Biochem 2009:42:885-91.

35 Caselli C, Cangemi G, Masotti S, et al. Plasma cardiac troponin I concentrations in healthy neonates, children and adolescents measured with a high sensitive immunoassay method: high sensitive troponin I in pediatric age. Clin Chim Acta 2016;458:68-71.

36 Koerbin G, Potter JM, Abhayaratna WP, et al. Longitudinal studies of cardiac troponin I in a large cohort of healthy children. Clin Chem 2012;58:1665-72. 
37 Abutaleb ARA, McNally EM, Khan SS, et al. Myocarditis in Duchenne muscular dystrophy after changing steroids. JAMA Cardiol 2018;3:1006-10.

38 Cinteza E, Stoicescu C, Butoianu N, et al. Acute myocardial injury in a child with Duchenne muscular dystrophy: pulse steroid therapy? Maedica 2017;12:180-3.

39 Cuccia C, Benedini G, Leonzi O, et al. [Acute myocardial infarction in a 13-year-old boy with Duchenne's disease]. G Ital Cardiol 1984;14:817-20.

40 Politano L, Palladino A, Petretta VR, et al. St-Segment displacement in Duchenne muscular dystrophy: myocardial necrosis or apoptosis? Acta Myol 2003;22:5-10.

41 Schoeffler M, Wallet F, Robert MO. Elévation de troponine I coronarographie normale chez un patient porteur d'une myopathie de Duchenne [Increased troponin I level in a Duchenne muscular dystrophy patient with normal coronarography]. Ann Fr Anesth Reanim 2008;27:345-7.

42 Feingold B, Mahle WT, Auerbach S, et al. Management of cardiac involvement associated with neuromuscular diseases: a scientific statement from the American heart association. Circulation 2017;136:e200-31.

43 McNally EM, Kaltman JR, Benson DW, et al. Contemporary cardiac issues in Duchenne muscular dystrophy. Working group of the National heart, lung, and blood Institute in collaboration with parent project muscular dystrophy. Circulation 2015;131:1590-8.

44 Bushby K, Finkel R, Birnkrant DJ, et al. Diagnosis and management of Duchenne muscular dystrophy, part 1: diagnosis, and pharmacological and psychosocial management. Lancet Neurol 2010;9:77-93.

45 Bushby K, Muntoni F, Urtizberea A, et al. Report on the 124th ENMC International workshop. treatment of Duchenne muscular dystrophy; defining the gold standards of management in the use of corticosteroids. 2-4 April 2004, Naarden, the Netherlands. Neuromuscul Disord 2004;14:526-34.

46 American Academy of Pediatrics Section on Cardiology and Cardiac Surgery. Cardiovascular health supervision for individuals affected by Duchenne or Becker muscular dystrophy. Pediatrics 2005;116:1569-73.

47 Parikh RH, Seliger SL, deFilippi CR. Use and interpretation of high sensitivity cardiac troponins in patients with chronic kidney disease with and without acute myocardial infarction. Clin Biochem 2015;48:247-53.

48 Viollet L, Gailey S, Thornton DJ, et al. Utility of cystatin C to monitor renal function in Duchenne muscular dystrophy. Muscle Nerve 2009;40:438-42.

49 Jia X, Sun W, Hoogeveen RC, et al. High-sensitivity troponin I and incident coronary events, stroke, heart failure hospitalization, and mortality in the ARIC study. Circulation 2019;139:2642-53.

50 Sandoval Y, Sharain K, Saenger AK, et al. Clinical use of cardiac troponin for acute cardiac care and emerging opportunities in the outpatient setting. Minerva Med 2019;110:139-56.
51 Raman SV, Hor KN, Mazur W, et al. Eplerenone for early cardiomyopathy in Duchenne muscular dystrophy: a randomised, double-blind, placebo-controlled trial. Lancet Neurol 2015:14:153-61.

52 Raman SV, Hor KN, Mazur W, et al. Eplerenone for early cardiomyopathy in Duchenne muscular dystrophy: results of a twoyear open-label extension trial. Orphanet J Rare Dis 2017;12:39.

53 Raman SV, Hor KN, Mazur W, et al. Stabilization of early Duchenne cardiomyopathy with aldosterone inhibition: results of the multicenter AIDMD trial. J Am Heart Assoc 2019;8:e013501.

54 Lowe J, Kolkhof P, Haupt MJ, et al. Mineralocorticoid receptor antagonism by finerenone is sufficient to improve function in preclinical muscular dystrophy. ESC Heart Fail 2020;7:3983-95.

55 Chadwick JA, Bhattacharya S, Lowe J, et al. Renin-AngiotensinAldosterone system inhibitors improve membrane stability and change gene-expression profiles in dystrophic skeletal muscles. Am J Physiol Cell Physiol 2017;312:C155-68.

56 Hauck JS, Howard ZM, Lowe J, et al. Mineralocorticoid receptor signaling contributes to normal muscle repair after acute injury. Front Physiol 2019;10:1324.

57 Hoffman EP, Schwartz BD, Mengle-Gaw LJ, et al. Cooperative international neuromuscular Research Group. Vamorolone trial in Duchenne muscular dystrophy shows dose-related improvement of muscle function. Neurology 2019;93:e1312-23.

58 Heier CR, Yu Q, Fiorillo AA, et al. Vamorolone targets dual nuclear receptors to treat inflammation and dystrophic cardiomyopathy. Life Sci Alliance 2019;2:e201800186.

59 Taylor M, Jefferies J, Byrne B, et al. Cardiac and skeletal muscle effects in the randomized HOPE-Duchenne trial. Neurology 2019;92:e866-78.

60 Wagner KR, Abdel-Hamid HZ, Mah JK, et al. Randomized phase 2 trial and open-label extension of domagrozumab in Duchenne muscular dystrophy. Neuromuscul Disord 2020;30:492-502.

61 Parent Project Muscular Dystrophy Webinar. Domagrozumab (anti-myostatin) as a potential treatment for Duchenne muscular dystrophy, 2019. Available: https://www.bing.com/videos/ search?q=PPMD+webinar+youtube+domagrozumab\&docid= $607991159651436986 \&$ mid $=69262$ C4747B046776CE669262C47 47B046776CE6\&view=detail\&FORM=VIRE [Accessed 13 Oct 2020].

62 Anderson J, Seol H, Gordish-Dressman H, et al. Interleukin 1 receptor-like 1 protein (ST2) is a potential biomarker for cardiomyopathy in Duchenne muscular dystrophy. Pediatr Cardiol 2017;38:1606-12.

63 Soslow JH, Xu M, Slaughter JC, et al. The role of matrix metalloproteinases and tissue inhibitors of metalloproteinases in Duchenne muscular dystrophy cardiomyopathy. J Card Fail 2019;25:259-67.

64 Magrath P, Maforo N, Renella P, et al. Cardiac MRI biomarkers for Duchenne muscular dystrophy. Biomark Med 2018;12:1271-89. 